\title{
Efficiency of Mandibular Arch Alignment with Self-Ligating and Conventional Edgewise Appliances: A Dental Cast Study
}

Diego A. Gaspar Ribeiro ${ }^{1}$, Marcio Rodrigues deAlmeida*, Ana Claudia Conti ${ }^{2}$, Ricardo Navarro ${ }^{2}$, Paula Oltramari-Navarro ${ }^{2}$, Renato Almeida $^{2}$ and Thais Fernandes ${ }^{2}$

${ }^{1}$ Graduate M.S. student, Department of Orthodontics, University of North Parana, Londrina-PR-Brazil

${ }^{2}$ Associate Professor, Department of Orthodontics, Universityof North Parana, Londrina-PR-Brazil

\begin{abstract}
Objective: To analyze and compare the efficiency of the correction of mandibular crowding between two types of bracket systems.

Material and method: According to the results of the power analysis for sample size calculation, 19 Angle Class I patients were included in the study and randomly divided into two groups: $G$ I $(n=10$, mean age 19.68years, min 13.86, max 28.78, self-ligating brackets), and GII ( $n=9$, mean age 20.98years, min11.13, max 29.85, conventional preadjusted brackets). To carry out this study, the sequence of wires used was similar for both groups. Dental casts were made available at the start of the treatment (T1), after 180 days of leveling and alignment (T2), and at the completion of leveling (mean, 600 days, T3). The degree of crowding was measured by means of Little's and Fleming's irregularity indexes, by using a Mitutoyo digital caliper. Student's t test and ANOVA were used to compare the efficiency of mandibular alignment between the two groups.
\end{abstract}

Results: The results showed that in the initial alignment phase (after 180 days), no statistically significant difference was found between the groups. On the other hand, from phase T1 to T3, it was observed a statistically significant difference between the groups regarding the correction of mandibular crowding.

Keywords: Orthodontics; Self-ligating brackets; Dental crowding

\section{Introduction}

In the past few years, we have observed a proliferation of preadjusted brackets with self-ligating systems, in that they have been offered as an advantage in orthodontic clinical practice [1,2]. According to their creators, self-ligating systems, when associated to the use of super elastic wires, offer excellent results to professionals regarding the time of treatment, in addition to light and continuous physiological strength during dental movement due to lower friction $[3,4]$.

Self-ligating brackets have a relatively long history. The first orthodontic device that did without ligatures existed as early as 1935 , when Stolzenberg in the United States proposed this concept (the Rusel Lock system) [5]. Many projects have been patented since then, although only a minority has become commercially available. Throughout the years, we have witnessed rapid changes in the technology of these brackets aiming at improving the efficiency of the system $[5,6]$.

Since self-ligatures reduce the resistance to dental movement, a number of studies reported the hypothesis that the treatment with selfligating brackets improves efficiency in terms of duration of treatment and number of appointments $[7,8]$. On the other hand, more recent studies by Miles [9] and Fleming et al. [10] found no improvement in the efficiency of the treatment, although Pandis et al. [11] verified that slight crowding was eliminated more rapidly with a Damon2 system than with conventional brackets in the hands of one same operator [11]. In two recent studies, Chen et al. [12] and Fleming PS and Johal A [13] carried out a systematic review aiming at verifying clinical evidence on the impact of self-ligating systems in orthodontic treatments. In the first study [11], the authors concluded that, despite the claims as to the clinical superiority of self-ligating brackets, and the fact that they seem to have significant advantages regarding chair time and incisor proclination (less than 1.5 degrees), no significant differences were found in the time of treatment and in occlusal characteristics between the two kinds of brackets. In the second study [12], the researchers also concluded that no sufficiently concrete scientific evidence exists to support the idea that self-ligating brackets effectively shorten the duration of treatment, although some studies attained statistical differences as to this factor.

Thus, despite the countless advantages attributed to self-ligating brackets, few papers available in the orthodontic literature today prove their efficacy in reducing mandibular crowding. Due to these considerations, the objective of this prospective study was to analyze and compare the efficiency to correct mandibular crowding between two types of bracket systems (self-ligating and conventional brackets).

\section{Material and Methods}

For this prospective study, 19 patients were randomly divided into two groups: Group I ( $\mathrm{n}=10$, mean age: 19.68years, min13.86, $\max$ 28.78), 5 females and 5 males: subjects using self-ligating brackets with a 0.022 x 0.027-inch slot (EasyClip, Aditek, Cravinhos, SP); and Group II ( $n=9$, mean age: 20.98years, min11.13, max 29.85) 7 females and 2 males: subjects using conventional pread justed brackets with a slot of $0.022 \times 0.030$-inch (3M Unitek, Monrovia, Calif).

All the patients presented Angle Class I malocclusion, with anterior crowding ranging from 5 to $12 \mathrm{~mm}$ (mean, $8.2 \mathrm{~mm}$ ). Only patients with complete permanent dentition, except third molars, were accepted

*Corresponding author: Marcio Rodrigues de Almeida, Orthodontic Department University of North Parana, Av. Jose Vicente Aiello 7-70, Bauru-São Paulo, Brazil, 17053-093, E-mail: marcioralmeida@uol.com.br

Received December 27, 2011; Accepted April 24, 2012; Published April 25, 2012

Citation: Gaspar Ribeiro DA, deAlmeida MR, Conti AC, Navarro R, OltramariNavarro P, et al. (2012) Efficiency of Mandibular Arch Alignment with Self-Ligating and Conventional Edgewise Appliances: A Dental Cast Study. Dentistry 2:128. doi:10.4172/2161-1122.1000128

Copyright: (C) 2012 Gaspar Ribeiro DA, et al. This is an open-access article distributed under the terms of the Creative Commons Attribution License, which permits unrestricted use, distribution, and reproduction in any medium, provided the original author and source are credited. 
for the study. Extraction of premolars and dental stripping were not included in the treatment proposed. Informed consent was signed by all parents or guardians of the patients after they received detailed information about the planned clinical trial and their children's future orthodontic treatment. This trial was approved by the ethical committee of University of North Paraná, UNOPAR, Londrina, Paraná, Brazil.

The patients were orthodontically treated during leveling and alignment for a mean total period of 600 days, with the same sequence of arch wires beginning with the $0.013,0.014,0.016,0.014 \times 0.025$, $0.016 \times 0.025,0.019 \times 0.025$-inch nickel-titanium arch wires and ending up with $0.019 \times 0.025$-inch stainless steel. According to the protocol chosen, each archwire remained for 60 days, and it was replaced in the previously mentioned sequence until lower alignment was reached. The archwires for Group II were attached to the brackets by means of using a metallic ligature. This fixation mechanism was done due to the fact that some papers reported that elastomeric ligatures lose great part of their initial strength as a result of rapid degradation [14-16].

The degree of crowding was measured by means of Little RM [17] and Fleming et al. regularity indexes. All models were obtained from using alginate, and hollowed in stone plaster, with the aid of a vibrator. In addition, biting plates with number 7 pink wax were prepared to articulate the models in intercuspation, and for subsequent cutting and finishing. Plaster models were taken at the beginning (T1), 180 days after having used the first three NiTi round wires (T2), and after leveling, (mean, 600 days) 0.019 X 0.025 stainless steel rectangular archwire (T3).

A calibrated digital caliper (Mitutoyo Digimatic Caliper) was used to measure the degree of mandibular crowding, with capacity for $150 \mathrm{~mm}$, and a $0.01 \mathrm{~mm}$ resolution. Modified tips were used in the horizontal direction to improve the accuracy of measurements.

\section{Statistical analysis}

The calculation of the sample of this study was based on a study conducted by Pandis et al. [18], with a reliability of $95 \%(\alpha=0.05)$, and a power of $80 \%(1-\beta)$ the required size of the sample was of nine patients for each group under study, totalizing 18 patients.

Forty-five days after the first evaluation, all the dental casts of the 19 patients were selected and the respective measurements were repeated in order to determine intra examiner errors, by means of using paired " $t$ " test (systematic errors) and Dahlberg formula (casual errors) [19].

The data were tested regarding the normal distribution applying Kolmogorov-Smirnov test. As the distributions were normal, parametric tests could be used. The results were described by parameters of mean and standard deviation of $\mathrm{T} 1, \mathrm{~T} 2$ and $\mathrm{T} 3$ measurements for both groups.

Variance Analysis for repeated measures and the post-hoc Tukey test for multiple comparisons between the three phases were also used. For the comparison between the groups, Student's t test was used. In all statistical tests, a $5 \%$ level of significance was set $(\mathrm{p}<0.05)$.

All statistical procedures were made with Statistica software (version 7.0; StatSoft Inc., Tulsa, Ok, USA).

\section{Results}

The results of the systematic error evaluations, made by the paired $t$ test, and of the causal error evaluations, as measured by the Houston WJ [19] formula showed that intra examiner agreement was excellent. No systematic intra examiner error occurred. In determining casual errors by means of the error calculation as proposed by Houston WJ [19], no significant difference was shown, there by proving intra examiner reliability.

The compatibility of the two groups in the beginning of the treatment can be seen in Table 1. A statistically significant difference was found as to Little RM [17] and Fleming et al. [10] indexes for mandibular crowding. According to Little RM [17] index, the initial average mandibular crowding for the self-ligating group was of 5.22 $\mathrm{mm}$, while that for the group treated with a conventional appliance

\begin{tabular}{|c|c|c|c|c|c|c|c|}
\hline \multirow{2}{*}{ Index } & \multicolumn{2}{|c|}{ Group I N=10 (Self-ligating) } & \multicolumn{2}{|c|}{ Group II N=9 (Control) } & \multirow{2}{*}{ Difference } & \multirow{2}{*}{$\mathrm{t}$} & \multirow{2}{*}{$\mathrm{P}$} \\
\hline & average $(\mathrm{mm})$ & SD & average $(\mathrm{mm})$ & SD & & & \\
\hline Fleming [7] & 11.02 & 3.88 & 5.09 & 2.90 & 5.93 & 3.631 & $0.002^{*}$ \\
\hline Little [19] & 5.22 & 2.04 & 2.39 & 0.94 & 2.83 & 3.779 & $0.002^{*}$ \\
\hline
\end{tabular}

statistically significant difference $(p<0.05)$

Table 1: Comparison between the two groups in the initial phase of Student's t test.

\begin{tabular}{|c|c|c|c|c|c|c|c|}
\hline \multirow{2}{*}{ Typeo f Bracket } & \multirow{2}{*}{ Index } & \multicolumn{2}{|l|}{$\mathrm{T} 1$ (Initial) } & \multicolumn{2}{|c|}{ T2 (180 days) } & \multicolumn{2}{|c|}{ T3 (afteralignment, 600 days) } \\
\hline & & average $\quad(\mathrm{mm})$ & $\mathrm{SD}$ & average $(\mathrm{mm})$ & $\mathrm{SD}$ & average $(\mathrm{mm})$ & SD \\
\hline \multirow{2}{*}{$\begin{array}{l}\text { Self-ligating } \\
\qquad N=10\end{array}$} & Little [19] & $5.22^{\mathrm{a}}$ & 2.04 & $2.58^{b}$ & 1.23 & $1.21^{\mathrm{c}}$ & 0.95 \\
\hline & Fleming [7] & $11.02^{\mathrm{a}}$ & 3.88 & $5.38^{b}$ & 2.15 & $1.73^{\mathrm{c}}$ & 1.04 \\
\hline \multirow{2}{*}{$\begin{array}{c}\text { Control } \\
N=9\end{array}$} & Little [19] & $2.39^{a}$ & 0.94 & $0.31^{b}$ & 0.38 & $0.08^{b}$ & 0.16 \\
\hline & Fleming [7] & $5.32^{\mathrm{a}}$ & 2.67 & $1.42^{\mathrm{b}}$ & 0.84 & $0.36^{c}$ & 0.43 \\
\hline
\end{tabular}

Times with different lower-case letters within the same group and index have a statistically significant difference between each other.

Table 2: Average and standard deviation of both groups, and the result of Variance Analysis and of the Tukey Test for the comparison between the three times. 


\begin{tabular}{|c|c|c|c|c|c|c|c|c|}
\hline \multirow{2}{*}{ Index } & \multirow{2}{*}{ Variation } & \multicolumn{2}{|l|}{ Self-ligating } & \multicolumn{2}{|c|}{$\begin{array}{c}\text { Control } \\
\mathrm{N}=9\end{array}$} & \multirow{2}{*}{ dif. } & \multirow{2}{*}{$\mathrm{T}$} & \multirow{2}{*}{$\mathrm{P}$} \\
\hline & & Average $(\mathrm{mm})$ & SD & Average $(\mathrm{mm})$ & $\mathrm{SD}$ & & & \\
\hline \multirow{3}{*}{ Little [19] } & $\mathrm{T} 2$ - T1 & -2.64 & 1.93 & -2.08 & 0.74 & 0.56 & -0.816 & $0.427 \mathrm{~ns}$ \\
\hline & T3 - T2 & -1.37 & 0.97 & -0.24 & 0.26 & 1.13 & -3.373 & $0.004^{*}$ \\
\hline & $\mathrm{T} 3-\mathrm{T} 1$ & -4.00 & 1.99 & -2.31 & 0.88 & 1.69 & -2.331 & $0.033^{*}$ \\
\hline \multirow{3}{*}{ Fleming [7] } & $\mathrm{T} 2$ - T1 & -5.64 & 2.69 & -3.90 & 2.09 & 1.74 & -1.535 & $0.144 \mathrm{~ns}$ \\
\hline & T3 - T2 & -3.64 & 2.04 & -1.06 & 0.76 & 2.58 & -3.552 & $0.003^{*}$ \\
\hline & T3 - T1 & -9.29 & 3.87 & -4.96 & 2.65 & 4.32 & -2.764 & $0.014^{*}$ \\
\hline
\end{tabular}

*- statistically significant difference $(p<0,05)$

ns - statistically non-significant difference

Table 3: Comparison between the two groups of the variations occurred in the three phases by Student's $t$ test.

was of $2.39 \mathrm{~mm}$. Regarding Fleming's index, an initial average of $11.02 \mathrm{~mm}$ was noted in the self-ligating group, and of $5.09 \mathrm{~mm}$, in the conventional group.

Table 2 shows that in both groups (self-ligating and conventional) a lower degree of crowding occurred between times $\mathrm{T} 2$ and $\mathrm{T} 3$, thereby indicating a significant improvement of mandibular crowding.

Student's $t$ test was used for the comparison between the two groups for the variations occurred in the three phases (T1, T2, and T3) as shown in Table 3. A statistically significant difference in the reduction of lower crowding for phases $\mathrm{T} 2-\mathrm{T} 3$ and $\mathrm{T} 1-\mathrm{T} 3$ can be seen. On the other hand, no statistically significant difference was found between the two groups regarding the effectiveness of the correction of lower crowding using the two indexes from phase T1 to T2.

\section{Discussion}

In the past few years, self-ligating brackets have received more attention in orthodontic practice, due to growing use of this selfligating mechanism. For this reason, many discussions have been put forward amongst clinical professionals and researchers [1,2,5,6,20]. Self-ligating brackets have been offered as a distinctive advantage for orthodondists who attempt to offer excellence treatment in the shortest time possible, and with a minimum number of appointments $[4,20]$.

A number of studies report that one of the main advantages of self-ligating brackets is the low friction between the bracket and the arch, preventing, thus, excessive proclination of anterior teeth, while leveling, in nonextraction cases [5,6,21]. In addition, the friction that occurs during dental movement by sliding mechanics may be influenced by various factors, such as: composition of the bracket and wire, wire section, type of binding, and inter-bracket distance $[8,15,21]$.

This study had a sample of nineteen subjects $(\mathrm{GI}=10$, and GII $=9$ ) whereas in most of the studies analysed in the literature, the number of subjects is over twenty patients for each group [9-11,22]. An important aspect is to expose the size of the sample, so that the research may have methodological quality, i.e., determining the sample is a fundamental part of any clinical trial. A number of factors negatively influenced the size of the sample used in this study, such as drop-outs (4 patients), move to a different city (1 patient), and lack of collaboration from the patient (7 patients). Various studies have reported the absence of credibility of the results due to a small size of the sample, and to a low testing power to detect clinically important differences [23]. Therefore, the sample calculation of this study was based on a study by Pandis et al. [18], in which it was found that to determine the size of the sample, formulae that take into account the following values are necessary: to estimate the number of subjects of the control group and of the group with the new therapeutic intervention, and to calculate of known statistical errors such as the alpha error (usually defined as 0.05 ) and the beta error (generallly fixed at 0.20 ). It must be noted that after the application of the formula proposed by Pandis et al. [18], and assuming the afore-mentioned data, wherein reliability is of $95 \%(\alpha=0.05)$, and the testing Power is of $80 \%(1-\beta)$, it was concluded that the size of the required sample would be of nine patients for each group under study, totaling 18 patients. Although a sample of a larger size would be desirable, the number of patients used in this study is sufficient to confer reliability to the results found. It must be emphasized that the present study analyzed patients that were not submitted to dental extractions or stripping in order to obtain information regarding the efficiency of mandibular alignment, by using two systems of brackets: both self-ligating and conventional.

In order to evaluate the error of the method, Houston [19] suggested that measurements be made twice. In this study, all the study models of the 19 patients were measured again, with an interval of 45 days after the first measurement. According to Houston [19], a greater number of casual errors occurs due to the difficulty of identifying certain points. In general, casual errors in this study were very reduced for Little RM [17] and Fleming et al. [10] irregularity indexes. The greatest meaning of casual errors refers to their power of increasing the standard deviation of the measurements obtained. Since the casual errors for the variables under study were small, it may be concluded that the standard deviations found for them are in fact the reflex of the variability of the measuerments in question.

Little RM [17] irregularity index was chosen to evaluate the lower crowding in plaster models, for it is highly reproduceable and reliable, and since it is the most widely used index in articles related to anteroinferior crowding in the literature $[9,11,22,24]$. Therefore, this index in this research made it possible to quantify the severity of the initial lower crowding, after 180 days of leveling, and that after leveling and alignemnt phase $(0.019 \mathrm{X} 0.025$ rectangular steel archwire). Aiming at aggregating value to this study, Fleming et al. [10] irregularity index 
(2009) was also included, the main characteristic of which is to take into account not only the 5 contact points that are proximal to the anterior teeth, but also another 6 values, totaling 11 points of anatomic contacts (from the mesial of the first right inferior molar to the mesial of the first left inferior molar).

To verify the compatibility of both groups, Student's t test was applied in the initial phase of the treatment, and a statistically significant difference was found for Fleming et al. [10] and Little RM [17] indexes for lower crowding. According to Fleming's index, the initial average for the self-ligating group was of $11.02 \mathrm{~mm}$, whereas for the group treated with a conventional appliance, the inital average was of 5.09 $\mathrm{mm}$. Regarding Little's index, an initial avearge of 5.22 was noted in the self-ligating group, and of $2.39 \mathrm{~mm}$ in the conventional group.This difference may be attributed to greater lower crowding in cases treated with self-ligating brackets, although the studies in the literature found that no significant difference existed in the initial crowding average between the two groups $[9,10,24]$.

The comparison between the two groups regarding the correction of crowding after 180 days of the treatment, obtained in this study, was of $2.64 \mathrm{~mm}$ for group I, and $2.08 \mathrm{~mm}$ for group II according to Little's irregularity index. On the other hand, in Fleming's index, reduction was of $5.64 \mathrm{~mm}$ for group I and $3.9 \mathrm{~mm}$ for group II, in that no statistically significant difference was found in the efficiency of the lower alignment during this phase. These results were similar to those found by other researchers [10,24,25]. Contrary to these results, Pandis et al. [11] noted a greater rate of alignment for the Damon system, i.e., patients with moderate crowding (irregularity index $<5$ ) were 2.7 times faster that those with conventional appliances $(\mathrm{P}<0,05)$, and patients with severe crowding were 1.37 times faster, as compared to conventional appliances, although without statistically significant difference. The authors concluded that self-ligating brackets had a faster effect on alignment in some cases, although this data had little clinical importance.

When the final phase of alignment (T1 to T3) was evaluated, it has been showed a significant difference in the correction of crowding of $4.00 \mathrm{~mm}$ for group 1, and of $2.31 \mathrm{~mm}$ for group II, according to Little's index. On the other hand, for Fleming's index, the value obtained was of $9.29 \mathrm{~mm}$ for self-ligating systems, and of $4.96 \mathrm{~mm}$ for the control group, indicating that even while using the $0.019 \times 0.025$ steel arch, group I had mild crowding (Little's index of $1.21 \mathrm{~mm}$ and Fleming's index of $1.73 \mathrm{~mm}$ ).This final crowding may be attributed to the difficulty that the operator had to place the rectangular wires after the end of the second phase (T2 -180 days), and one may adduce, thus, that the change of the arch could be made in a period longer than eight weeks, especially in group I, in which the sample had greater crowding as compared to the control group. Although self-ligating and conventinal systems showed a statistical difference to correct lower crowding from T1 to T3 (Little's index of $1.69 \mathrm{~mm}$, and Fleming's index of $4.32 \mathrm{~mm}$ ), and from T2 to T3 (Little's index of $1.13 \mathrm{~mm}$ and Fleming's index of $2.58 \mathrm{~mm}$ ), this may be justified by the initial difference of the lower crowding in group I in relation to group II - which disagrees with the results shown by Scott et al. [26] and Dibiase et al. [27] Nevertheless, broader and more consistent results regarding the efficiency of selfligating and conventional brackets in anterior alignment, which are compatible in both groups as per initial crowding, may complement this study in order to contribute to the correct use of these appliances.

Various investigations have analyzed the hypothesis that treatments with self-ligating brackets offer improved efficiency in terms of the duration of the treatment and number of visits, in addition to a reduction in the time of appointments $[28,29]$. A more rapid treatment with fewer visits to the office would clearly be an advantage from the point of view of patients, and would also have a better cost-benefit relationship. Harradine [5] compared the efficiency of self-ligating brackets and verified an average reduction of four months in the time of active treatment from 23.5 to 19.4 months, and an average reduction of four visits during active treatment from 16 to 12 . On the other hand, in another study carried out by Ebeting et al. [7], they found an average reduction in the time of treatment of 5 months (from 30 to 23) and 7 appointments (form 28 to 21) for cases of Damon SL as compared to conventional brackets. However, in the present study, this reduction in the time of treatment was not observed in initial phase of alignment (first 180 days), corroborating the studies by Fleming et al. [10,25] and Ong et al. [22] who did not find statistically significant differences in the efficiency of inferior alignment.

Miles et al. [24] conducted two different studies, with similar protocols, wherein they compared the variables of treatment between conventional and self-ligating brackets. In the first study, they compared the Damon 2 self-ligating system with the conventional bracket system (Victory, 3M), by bonding a Damon 2 bracket onto one side of the lower arch, and a conventional appliance, on the other side. The irregularity index was measured for each half of the arch in the beginning, ten weeks after the first arch, and another ten weeks after changing to the second arch. The authors concluded that the conventional bracket reached a lower index of irregularity than the self-ligating system. In the present study, it was noted that after 180 days of alignment, no statistically significant difference was found in the irregularity index between the two groups, i. e., both systems showed similar efficiency during the initial alignment. This results were also found in the study conducted by Miles [9].

Nevertheless, it is essential to point out that most studies that showed an excellent performance of self-ligating systems as compared to the conventional system were in vitro trials [4]. Recent studies on the efficiency of lower crowding correction, using self-ligating brackets, are less enthusiastic [10-12,22,26,27]. Moreover, to attribute the rapidness of the alignment to the bracket does not seem feasable, for what levels the teeth are the wires, and not the brackets. Thus, we may state that the self-ligating bracket system does not seem to afford the developement of a more rapid or more efficient plan of treatment than the conventional bracket systems. It must be emphasized that the self-ligating bracket system is one more option for Orthodontists, and their choice must be based on the ability and experience of each professsional, and not only rely in the promise of obtaining more efficient results.

At this point, it is important to point out that further studies with a larger sample may be required to assess and compare the results with our study. Obviously, the results found in this study, using brackets and a system of exchanging orthodondic archwires, must not be extended to other trials. Moreover, it must be emphasized that research works with a longer follow-up time may be required, in order to foster a correct use of self-ligating appliances, for the existing scientific evidence does not seem to support the idea that self-ligating bracket systems are effectively more efficient to correct lower arch dental crowding.

\section{Conclusion}

No statistically significant differences were found in the correction of lower dental crowding during the initial phase of alignment, regardless of the kind of bracket used (self-ligating or conventional). 
Citation: Gaspar Ribeiro DA, deAlmeida MR, Conti AC, Navarro R, Oltramari-Navarro P, et al. (2012) Efficiency of Mandibular Arch Alignment with Self-Ligating and Conventional Edgewise Appliances: A Dental Cast Study. Dentistry 2:128. doi:10.4172/2161-1122.1000128

Page 5 of 5

A statistically significant difference was found between phase $\mathrm{T} 2$ (180 days) to phase T3 (end of alignment).

\section{References}

1. Berger JL (1990) The influence of the SPEED bracket's self-ligating design on force levels in tooth movement: a comparative in vitro study. Am J Orthod Dento facial Orthop 97: 219-228.

2. Berger JL (2000) Self-ligation in the year 2000. J Clin Orthod 34: 74-81.

3. Berger JL, Byloff FK (2001) The clinical efficiency of self-ligated brackets. J Clin Orthod 35: 304-308.

4. Damon DH (1998) The Damon low-friction bracket: a biologically compatible straight-wire system. J Clin Orthod 32: 670-680.

5. Harradine NW (2001) Self-ligating brackets and treatment efficiency. Clin Orthod Res 4: 220-227.

6. Harradine NWT (2008) The history and development of self-ligating brackets. Semin Orthod 14: 5-18.

7. Eberting JJ, Straja SR, Tuncay OC (2001) Treatment time, outcome, and patient satisfaction comparisons of Damon and conventional brackets. Clin Orthod Res 4: 228-234.

8. Henao SP, Kusy RP (2005) Frictional evaluations of dental typodont models using four self-ligating designs and a conventional design. Angle Orthod 75: 75-85.

9. Miles PG (2005) SmartClip versus conventional twin brackets for initial alignment: is there a difference? Aust Orthod J 21: 123-127.

10. Fleming PS, DiBiase AT, Sarri G, Lee RT (2009) Efficiency of mandibular arch alignment with 2 preadjusted edgewise appliances. Am J Orthod Dento facial Orthop135: 597-602.

11. Pandis N, Polychronopoulou A, Eliades T (2007) Self-ligating vs conventional brackets in the treatment of mandibular crowding: a prospective clinical trial of treatment duration and dental effects. Am J Orthod Dento facia IOrthop 132 208-215

12. Chen SS, Greenlee GM, Kim JE, Smith CL, Huang GJ (2010) Systematic review of self-ligating brackets. Am J Orthod Dentofacial Orthop 137: 726.e1726.e18.

13. Fleming PS, Johal A (2010) Self-ligating brackets in orthodontics. A systematic review. Angle Orthod 80: 575-584.

14. Hain M, Dhopatkar A, Rock P (2003) The effect of ligation method on friction in sliding mechanics. Am J Orthod Dento facial Orthop 123: 416-422.

15. Khambay B, Millett D, McHugh S (2004) Evaluation of methods of archwire ligation on frictional resistance. Eur J Orthod 26: 327-332.

16. Taloumis LJ, Smith TM, Hondrum SO, Lorton L (1997) Force decay and deformation of orthodontic elastomeric ligatures. Am J Orthod Dento facial Orthop 111: 1-11.

17. Little RM (1975) The irregularity index: a quantitative score of mandibular anterior alignment. Am J OrthodDentofacialOrthop 68: 554-563.

18. Pandis N, Polychronopoulou A, Eliades T (2011) Sample size estimation: An overview with applications to orthodontic clinical trial designs. Am J Orthod Dento facial Orthop 140: e141-e146.

19. Houston WJ (1983) The analysis of errors in orthodontic measurements. Am $J$ Orthod 82: 382-390.

20. Harradine N (2009) Northcroft Memorial Lecture self-ligation: past, present and future. J Orthod 36: 260-271.

21. Kim TK, Kim KD, Baek SH (2008) Comparison of frictional forces during the initial leveling stage in various combinations of self-ligating brackets and archwires with a custom-designed typodont system. Am J Orthod Dento facial Orthop 133: 187.

22. Ong E, McCallum H, Griffin MP, Ho C (2010) Efficiency of self-ligating vs conventionally ligated brackets during initial alignment. Am J Orthod Dento facial Orthop 138.

23. Moher D, Dulberg CS, Wells GA (1994) Statistical power, sample size, and their reporting in randomized controlled trials. JAMA 272: 122-124.

24. Miles PG, Weyant RJ, Rustveld L (2006) A clinical trial of Damon 2 vs conventional twin brackets during initial alignment. Angle Orthod 76: 480-485.

25. Fleming PS, DiBiase AT, Lee RT (2010) Randomized clinical trial of orthodontic treatment efficiency with self-ligating and conventional fixed orthodontic appliances. Am J Orthod Dento facial Orthop 137: 738-742.

26. Scott P, DiBiase AT, Sherriff M, Cobourne MT (2008) Alignment efficiency of Damon3 self-ligating and conventional orthodontic bracket systems: a randomized clinical trial. Am J Orthod Dento facial Orthop 134: 470.

27. Dibiase AT, Nasr IH, Scott P, Cobourne MT (2011) Duration of treatment and occlusal outcome using Damon3 self-ligated and conventional orthodontic bracket systems in extraction patients: A prospective randomized clinical trial. Am J Orthod Dento facial Orthop 139: e111-e116.

28. Maijer R, Smith DC (1990) Time savings with self-ligating brackets. J Clin Orthod 24: 29-31.

29. Turnbull NR, Birnie DJ (2007) Treatment efficiency of conventional versus selfligating brackets: the effects of archwire side and material. Am J Orthod Dento facial Orthop 131: 395-399. 